\title{
A Discussion on Ideological Education for Chinese College Students against the Background of Microcultures
}

\author{
Aitang Zuo \\ Feixian Campus of Linyi University, Feixian 273400, China. \\ fsz006@126.com
}

\begin{abstract}
With the rapid development of science and technology, especially the birth of the mobile Internet, microcultures have increasingly permeated college students' daily life and influenced contemporary college students' thinking and life. Chinese universities, society and mass media should join hands to make full use of microcultures to provide a new way and tool for correct philosophy and values education for college students.
\end{abstract}

Keywords: Microcultures; college students; Ideological education; Innovation in ways.

\section{Introduction}

The rapid development of science and technology, especially the birth of the mobile Internet, has resulted in a series of cultural products characterized by "micro-", such as MicroBlog, WeChat (micro message), microfilm, and micro-fiction, which have quickly become popular among people especially college students. Due to the low thresholds and virtualization of we media such as MicroBlog and WeChat, the content of microcultures has become diverse. As a result, while being spiritually and culturally enriched by microcultures, people are also adversely affected by frequently exposing themselves to various types of microcultural information via mobile terminals such as mobile phones. College students are receptive to new things, eager to show their individuality but immature. Currently, microcultures are enormously and widely influencing the thinking and life of contemporary college students.

\section{The Status Quo of the Application of Microcultures by College Students}

On January 22, 2016, the China Internet Network Information Center (CNNIC) published the 37th Statistical Report on Internet Development in China. According to the report, there were 688 million Chinese netizens in December 2015, with an Internet penetration rate of 50.3\%. In 2015, there were 39.51 million new netizens, and Chinese netizens achieved a growth rate of $6.1 \%, 1.1 \%$ higher than that achieved in 2014. By December 2015, there had been 620 million Chinese mobile phone netizens, a percentage of $90.1 \%$, and there had been 127 million Chinese netizens who only use mobile phones to access the Internet, accounting for $18.5 \%$ of the total netizens. [1]

College campuses are filled with numerous vigorous college students. Due to their embrace of new things, college campuses have become places for the development of new things. Things beginning with "micro" such as micro message and microblog have quickly become popular throughout college campuses immediately they emerged.

\subsection{Microcultures Have Been Widely Popular Among College Students and Have Permeated Their Daily Life.}

With the rapid development of mobile devices such as mobile phones and computers as well as mobile communication technology, almost every college student has both a mobile phone and a computer or at least either of them, which makes it inevitably possible for college students to use or expose themselves to the currently most popular microcultural communication platforms such as WeChat and MicroBlog. As a result, everyone uses WeChat and MicroBlog. College students have become a major force of netizens, and the wide popularity of microcultural communication platforms among college students have become an established fact. 
Due to the ease of use of mobile devices such as smart phones and mobile data traffic, college students can use the Internet anywhere and anytime. Whether in university campuses, classrooms or dormitories or in the street, on the bus or in the shopping mall, college students can be found using their mobile phones to access WeChat, post microblogs, and view micro-videos. They share with MicroBlog and WeChat Moments whatever happens in their study and life. Microcultures have become a normal in the daily life of contemporary college students. In addition, with the integration of electronic platforms such as WeChat and commerce, derivatives such as micropayment and micro-advertising have also increasingly become powerful tools used by college students to start their own business and do shopping. Overall, microcultural communication platforms have increasingly permeated college students' daily life and become an indispensable part of their life.

\subsection{More and More College Students Have Become "Phubbers" and Rely on Microcultures.}

The close combination of microcultural communication platforms with college students' daily life has resulted their strong reliance on microcultural communication platforms, as evidenced by the emergence of various addicts such as WeChat addicts and MicroBlog addicts. According to the Statistical Reports on Internet Development in China, with the rapid development of various Internet applications, the Internet has increasingly become an integral part of netizens' daily work, life, and study, and people are becoming increasingly dependent upon networks. Moreover, netizens' dependence upon the Internet increases with their level of education. College students in the micro era have been alienated by microcultural communication platforms and have had a strong reliance upon them. In particular, the use of smartphones has made access to the Internet using mobile phones a primary way for current college students to obtain information, communicate, and express their feelings. They are addicted to digital recreation and focus on the consumption and comparison of digital products such as mobile phones and tablets. Phubbing is becoming increasingly prominent. Some college students even spend their school hours browsing MicroBlog and Moments. College students are keen to interact and communicate in a virtual environment and focus little on realistic communication with their families and classmates. [2]

\section{Feasibility of Use of Microcultures for Ideological Education for College Students}

\subsection{Use of Microcultures Can Increase the Time and Space for Ideological Education for College Students.}

The development of networks and the mobile Internet has changed the traditional mode dominated by classroom teaching. The emergence of networks makes learning an easy thing. Anyone can listen to the courses taught by teachers from world-famous universities and interact and communicate via MicroBlog and forums as long as he will, which transcends the time and space limitations of ideological education for college students.

\subsection{The Development of Microcultures Can Improve the Currency of Ideological Education for College Students.}

Today, when information spreads rapidly, it is easier for people to obtain the truest information as soon as possible. Not only hot issues in the international community, sensitive issues in national political life, and focuses in social life, but also the personal emotional disputes of public figures, can quickly draw college students' sustained attention. Efficient platforms such as MicroBlog and WeChat make it easier for college students to learn and absorb latest ideas. [3]

\subsection{The Development of Microcultures Can Enrich the Content and Means of Ideological Education for College Students.}

The ideological education for Chinese college students focuses primarily on Marxism and the theory of socialism with Chinese characteristics in textbooks. This content is often taught in a single form and therefore cannot attract college students' interest. In the micro era, diversified speeds of spread and high-speed information updating constantly enrich the content of universities' ideological education and make themes more attractive and more up to date. Ideological educators can make use of some currently popular network media and impart network information in the new situation that 
resonates with college students in order to make ideological education permeate every corner of the society.

\section{Ways of Using Microcultures to Provide Ideological Education for College Students}

Since the development of microcultures has been a trend and college students are increasingly influenced by microcultures, universities and colleges need to keep pace with the times, frankly face current changes, and become fully aware of the potential communication value of MicroBlog, WeChat and micro public welfare against the background of microcultures. Full use can be made of them to provide a new way and tool for college students to foster correct philosophies and values.

\subsection{Colleges and Universities Can Make Use of Microcultural Platforms to Establish a Diversified Microcutural System in Order to Enrich Campus Activities.}

Colleges and universities should make full use of MicroBlog and WeChat to timely reprint or publish positive values and information in order to promote the transmission of positive educational content. By launching an official microblog or opening WeChat public platform, colleges and universities use microcultural platforms to incorporate mainstream cultures into microcultures in a concise form, which can not only provide college students with imperceptible education by promoting the transmission of mainstream cultures in a manner acceptable to college students, but also increase the depth and breadth of campus microcultures. The characteristics of microcultures determine their great tolerance, and they can incorporate various cultures. Colleges and universities can take advantage of microcultures and create a diversified system of campus microcultures on the premise of sticking to campus mainstream. The development of microcultures reduces the spatial distance between teachers and students, students and students, and universities and universities, and provides a new platform for carrying out colorful campus activities. Universities can invite some experts or social celebrities in the name of a university or a school to interviews conducted using MicroBlog or WeChat, and hold debates on hot topics using MicroBlog or WeChat and contests for themes of educational activities in order to help college students foster correct values during participating in activities conducted using MicroBlog and WeChat. Relevant departments of colleges can also join hands with other colleges to organize teachers and students to participate in exchange and study tours across colleges in order to broaden students' horizons. In addition, college students should be encouraged to form clubs for microfilms and micro public welfare, and relevant activities should be organized to enable college students to improve themselves by participation. These meaningful campus activities are expected to positively affect college students' values. [4]

\subsection{To Purify Network Environments by Strengthening Governmental Network Regulation.}

Networks are the fertile soil that breeds microcultures. Without networks, microcultures would lose the hotbed for growth. Therefore, networks are the origin of microcultural information, and the renovation and management of microcultural environments must start with network regulation. Network regulation is a complex, long-term task that requires the government to play its positive role. First, the government must further improve the rules and regulations on the management of network microcultures, strictly control network information publishing platforms, timely filter out adverse information, strictly crack down on outlaws that start and spread rumors, and strictly insist on regulating networks according to law. Second, efforts should be made to innovate and improve network propaganda, and network propagation characteristics should be based on to promote the themes of the times, inspire positive energy, vigorously foster and practice core values, and grasp the timing, degree, and utility of the guidance of online public opinion.

\subsection{To Spread Positive Energy by Giving Play to Mass Media's Guidance of Public Opinion.}

Mass media assume the task of shaping the entire social landscape. They must give play to their positive guidance, communicate scientific, healthy, and civilized values to their audience, and do their best to help college students' foster correct values. Currently, the production and communication of information have entered the micro era, when microcultural platforms such as MicroBlog, WeChat, and microfilm have exerted increasing influence and are favored especially by young people. Under 
these circumstances, the coverage of mass media is required to adapt to the characteristics of the micro era and give play to the advantages of microtechnology. Microcultural platforms should be used to widely spread core values in order to fill the environment for microcultural communication with mainstream values. Additionally, the coverage of state affairs, hot social issues, and moral examples should be increased, and concrete, vivid cases should be used to resonate with college students in order to influence their thought and psychology. Microcultures are spread through technological platforms such as MicroBlog and WeChat, so media enterprises such as Tencent and Sina must assume their social responsibility and actively regulate the background of software such as MicroBlog and WeChat. They must exercise strict control over users that release and reprint adverse information by warning such users, reducing their permissions or even directly blocking their registered account, rather than disregard professional ethics and social morality simply for the purpose of pursuing commercial interests.

\subsection{To Improve College Students' Ability to Screen Information in Order to Help Them Make Reasonable and Moderate Use of Networks.}

College students should not only be encouraged to keep pace with new things, but also are required to focus on their study. They must improve their control over networks and have good judgment about network morality, exercise their control over information, not to forward or comment on information that is uncertain and obviously negative, and consciously restrain themselves from being eroded and poisoned by adverse information. They must make reasonable use of their time, instead of spending excessive time and energy on networks, and must refuse to become MicroBlog addicts and develop a good habit of using MicroBlog, Wechat, and Microfilm. Meanwhile, as the participant and creator of network environments, our college students are under an obligation to constantly improve their ability to screen information by relying on their knowledge. When necessary, they must stand out as an information policeman that participates in denying rumors and confirmation and become a creator of a safe, clean network environment. College students should have a noble ideal, learn to think calmly, and avoid being blind and following suit. [5]

\section{Summary}

Chinese colleges must actively use MicroBlog and WeChat to provide college students with a platform in which their can participate directly, and create a healthy "microcultural" atmosphere for ideological education so as to promote cultures with microcultures. Overall, colleges must make full use of microcultures to improve the effectiveness of ideological education for college students in multiple ways so as to promote the overall development of college students.

\section{References}

[1]. Information on

http://www.cnnic.net.cn/hlwfzyj/hlwxzbg/hlwtjbg/201601/t20160122_53271.htm (In Chinese)

[2]. X.C. Hua, Micro Culture, the New Dimension of the Ideological Guidance of Campus Culture Activity in Colleges and Universities. Heilongjiang Researches on Higher Education. No. 7 (2015), p. 41-43 (In Chinese)

[3]. A. M. Tang and L. P. Yang, A Discussion on the Characteristics, Functions, and Applications of Microcultures. Ideological \& Theoretical Education. No. 6 (2013), p. 11-15 (In Chinese)

[4]. L. N. Yu, Effects of the WeChat Era on Contemporary College Students and Analysis of Countermeasures. Journal of China University of Geosciences (Social Sciences Edition). No. S1 (2014), p. 156-157 (In Chinese)

[5]. C. X. Li, Research about the Micro-cultural Influence on the Value Education of Undergraduates and Countermeasures: (MS., Liaoning University, China2015) (In Chinese) 